\title{
The impact of renewable injections on cycling of conventional power plants
}

\author{
Kenneth Van den Bergh, Erik Delarue and William D'haeseleer \\ Energy Institute \\ TME Branch (Applied Mechanics and Energy Conversion) \\ University of Leuven (KU Leuven)
}

\begin{abstract}
Renewable injections from wind and solar affect the variability in residual electricity demand (demand minus renewable injections) to be covered by the conventional electricity generation system. In order to meet the variable residual demand, conventional power plants are required to cycle, meaning that they have to change their generation output by ramping or switching on/off. As cycling of conventional power plants entails technical and economical issues, it is imperative to know the effect of increasing renewable injections on cycling. This paper quantifies conventional power plant cycling as function of the amount of renewable injections. The results follow from a unit commitment model of a realistic electricity system. The study shows that the change in variability in residual demand due to renewable injections is rather limited. The way conventional power plants meet this variable demand, however, changes considerably as renewable injections force more base load plants to cycle. The take-away of this paper is that required flexibility from the conventional power plant portfolio is not the issue; the way this flexibility is delivered is the issue when it comes to conventional power plant cycling.
\end{abstract}

Index Terms-Renewable electricity injections, variability in electricity demand, cycling of conventional power plants.

\section{INTRODUCTION}

As a result of the support for renewable electricity from wind and solar energy, installed wind and photovoltaic capacity has increased dramatically over the last few years. In September 2012, the total installed wind power capacity in the European Union passed the milestone of $100 \mathrm{GW}$. Five years ago only $48 \mathrm{GW}$ wind power was installed and 15 years ago, barely any wind turbines were in operation [1]. The growth in photovoltaic capacity is perhaps even more astonishing. By the end of 2011, the installed photovoltaic capacity in the EU was $46 \mathrm{GW}$ [2]. Five years ago, the installed photovoltaic capacity amounted only $5 \mathrm{GW}$ [3].

This paper focusses on the cycling of conventional power plants due to the variable and non-dispatchable character of renewable injections from wind and solar. Wind and solar are intermittent power sources, meaning that their generation is variable and - to a certain extent - unpredictable; as a consequence also, their generation is non-dispatchable. Therefore, renewable injections from wind and solar have important implications on the required level of system reserves and the rate at which these reserves can be deployed [4]. Part of the operational reserve is provided by conventional power plants which can increase or decrease their power output by cycling. Cycling is defined as starting-up, shutting down, ramping up and ramping down a power plant [5] [6]. This paper only considers the variable character of renewables. This means that power plant operators are assumed to have perfect knowledge of actual wind and solar generation. The partially unpredictable character of wind and solar is not taken into account.

Cycling has a degenerating effect on power plants. When a generation unit varies its output, components in the unit are subject to stresses and strains. During the shut down of a unit, components undergo large temperature and pressure stresses [7]. These stresses and strains lead to accelerated component failures and forced outages [8]. Starting up a unit is even more demanding. Wear and tear on the components of the generation units is exacerbated by a phenomenon known as creep-fatigue interaction [7]. In [9], the authors refer to several sources in the literature dealing with other cycling related issues. The cost associated with power plant cycling consists of several components: the operations and maintenance cost related to degeneration of components, the capital cost to replace degenerated components, the opportunity cost of not operating during an outage and the cost for fuel, $\mathrm{CO}_{2}$ emissions and auxiliary power needed for start-up [10]. Most operators only take the fuel and $\mathrm{CO}_{2}$ emission cost for a start-up into account when making the unit commitment decision, although this cost is quite small relative to the total cycling cost [8]. The total cycling cost depends on many factors like the type and age of the power plant and the way of operating. Therefore it is difficult to put a number on the total cycling cost of a power plant. According to [8], it is estimated that cycling costs of conventional fossil-fuel fired power plants can range from $\$ 2,500$ to $\$ 500,000$ per single on-off cycle, depending on the specific unit size, type, age, usage pattern, etc. In this paper, only the fuel and $\mathrm{CO}_{2}$ emission cost for a start-up is taken into account during the unit commitment decision as mostly operators neglect costs related to component degeneration. For the sake of simplicity, only one start-up cost per power plant type is used, in range with other sources in the literature.

Following on this introduction, section II deals with the used methodology and section III presents the results. Finally, section IV concludes. 


\section{Methodology}

This paper examines the impact of renewable injections from wind and solar on cycling of conventional power plants. The research question splits up in 2 sub questions:

- How does the variability in residual demand change as function of renewable injections?

- How does the conventional power plant portfolio meet this variable residual demand? Which power plants cycle and how often do they cycle?

Both questions are answered by means of a Mixed-Integer Linear Program (MILP) that simulates the Unit Commitment and Economic Dispatch (UC ED) decision of a realistic electricity system for different levels of renewable injections from wind and solar.

\section{A. System description}

The considered electricity system consists of an inelastic electricity demand time series and a set of generation units. All generation units and consumers are located at one single node. The electricity system is based on the 2010 German system. However, this is not a German case study. Some simplifications are made to keep the study more general and conceptual. One of the most important assumptions is the neglect of grid congestions as no electricity grid is included in the model. As pointed out by Bruninx et al. [11], the transmission grid in Northern Germany would be critical for a German case study.

The portfolio of generation units consist of non-dispatchable units (i.e. generation from wind, solar, conventional hydro ${ }^{1}$, bio-energy and waste, and combined heat and power production $)^{2}$, and dispatchable units consisting of pump units and conventional power plants (i.e. nuclear power plants, steam power plants on lignite and coal, combined cycle power plants on natural gas and gas turbines on natural gas and fuel oil). Steam power plants dominate the conventional power plant portfolio (see table I). Note that the term steam power plants refers in this paper only to coal fired and lignite fired steam power plants, not to combined cycle units which also have a Rankine cycle. The nuclear power plants which were shut down in May 2011, immediately after the nuclear phase-out decision by the German government, have been kept in operation in the analysis (which refers to the German system of 2010). Table I summarizes the technical and economical parameters of the different power plant technologies. The lowest rated efficiency is used for power plants commissioned before 1980, while the middlemost efficiency is used for units commissioned between 1980 and 2000 and the highest efficiency is used for power plants commissioned or retrofitted after 2000. Minimum power

\footnotetext{
${ }^{1}$ Run-of-river units and water dams are conventional hydro units.

${ }^{2}$ Power plants on biomass, biogas and waste, and combined heat and power units are driven by respectively remuneration mechanisms and heat demand, therefore they are considered non-dispatchable from a market point of view. Nevertheless, from a technical point of view, they can be dispatched as any other conventional power plant.
}

output and ramping rates are expressed as a percentage of maximum power output $\bar{P}$ of the unit. The minimum downtime covers the time for cooling down a power plant after operation and the time to restart and synchronize a power plant again with the grid. No minimum uptime is considered as every power plant can be taken off-line at any time. A fixed $\mathrm{CO}_{2}$ emission price of $14.50 \mathrm{EUR} / \mathrm{tCO}_{2}{ }^{3}$ is assumed to determine the $\mathrm{CO}_{2}$ emission cost. The average no load cost is the average production cost at minimum power output. The start-up cost includes the fuel cost and $\mathrm{CO}_{2}$ emission cost for a start-up and is expressed as a fixed cost times the minimum power output of the unit, indicating that larger power plants have higher start-up costs. A requirement of minimum $1400 \mathrm{MW}$ spinning reserve is imposed to the system [12].

In the analysis, the conventional power plant portfolio has been divided in low dynamic and high dynamic power plants, based on the historical use of these units. Nuclear power plants and steam power plants are low dynamic power plants. These units are modeled with small ramping rates, large minimum down times and high start-up costs. Combined cycle units and gas turbines are high dynamic power plants, having large ramping rates, small minimum down times and low start-up costs. Technically, though, steam power plants and nuclear power plants can be dispatched very dynamically, and this is foreseen for new plants of these types to come on-line in the future.

The amount of renewable injections from wind and solar is varied between $0 \mathrm{TWh} /$ year and $100 \mathrm{TWh} /$ year, corresponding to a renewable share in final electricity consumption of 9.5 $\%$ to $26 \%$ and as such in line with the European renewable target ${ }^{5}$. The historical generation for Germany from wind and solar in 2010 was $50 \mathrm{TWh}$. The generation profile of wind and solar is based on the historical generation profile. The model assumes perfect knowledge of the renewable generation from wind and solar. Only the variable character of these injections is thus addressed. The possibility of renewables curtailment is implemented in the model. This means that reduction of renewable generation can be preferred to down-cycling of power plants to maintain the supply-demand balance [15].

Information on the available conventional generation capacity originates from the Umweltbundesamt [16] and electricity demand from ENTSO-E [17]. The original electricity demand is scaled with a factor that compensates for the neglected import or export. The wind generation profile is based on historical data from German TSOs [18] [19] [20] and the solar

\footnotetext{
${ }^{3}$ The 2010 average $\mathrm{CO}_{2}$ emission price is $14.50 \mathrm{EUR} / \mathrm{tCO}{ }_{2}$.

${ }^{4}$ Including other renewable electricity sources which are kept constant at historical generation.

${ }^{5}$ The overall European renewable target is a $20 \%$ renewables share in final energy consumption by 2020 , with a $18 \%$ renewables share as target for Germany. As the electricity sector is a relatively easy sector to deploy renewables, the renewable electricity share is expected to be above the overall target.
} 
TABLE I

Overview of the conventional power Plant portfolio. SPP are Steam Power Plants, CCGT are Combined CyCle Gas Turbines, oCGT are Open Cycle Gas Turbines. $\bar{P}$ Is the maximum power output of the Unit. [13] [14]

\begin{tabular}{l|ccccc} 
& Nuclear & SPP Lignite & SPP Coal & CCGT & OCGT \\
\hline Available capacity $[G W]$ & 16.2 & 15.2 & 16.3 & 15.1 & 3.7 \\
Rated efficiency [\%] & 33 & $38 / 42 / 45$ & $38 / 42 / 45$ & $52 / 56 / 60$ & $30 / 31 / 32$ \\
Minimum power output $[\% \bar{P}]$ & 40 & 30 & 30 & 45 & 30 \\
Ramp-up/ramp-down rate $[\% \bar{P}]$ & \pm 40 & \pm 40 & \pm 40 & \pm 100 & \pm 100 \\
Start-up/shut down rate $[\% \bar{P}]$ & \pm 40 & \pm 50 & \pm 50 & \pm 100 & \pm 100 \\
Minimum downtime $[h]$ & 48 & 6 & 6 & 2 & 1 \\
Fuel cost $\left[E U R / M W h_{\text {prim }}\right]$ & 2,3 & 1,5 & 10 & 20 & $20 / 38$ \\
$\mathrm{CO}_{2}$ emission cost $\left[E U R / M W h_{\text {prim }}\right]$ & 0 & 5.7 & 5.4 & 3.3 & $3.3 / 4.4$ \\
Average no load cost $[E U R / h]$ & 3,530 & 2,814 & 4,958 & 6,512 & 7,284 \\
Start-up cost $\left[E U R / h / M W_{\text {min }}\right]$ & 15 & 10 & 10 & 5 & 0
\end{tabular}

generation profile is based on solar irradiation data [21]. All data from different sources is scaled to match aggregated data from Eurelectric [22] to overcome deviation between different data sources.

\section{B. Model description}

The results presented in this paper follow from a deterministic MILP model, specifically built for this study, that simulates the unit commitment and economic dispatch decision for the given electricity system. The model is formulated in the General Algebraic Modeling System (GAMS) and solved using the CPLEX 12.3 solver. The model simulates one year in blocks of two days at a time with successive blocks overlapping one day. The UC ED of the first day is saved and used as starting value for the next block. Simulating two days in a row ensures that power-plant operators take into account, when making the unit commitment decision for the first day, the implications of this decision for the next day. The used time step is one hour.

The mathematical description of the model is based on the work of Carrión and Arroyo [23] and adapted to include pump storage. The power plants are committed and dispatched in a way that electricity demand is met at minimal overall cost. This cost consists of a production cost and a start-up cost. The objective function is

$$
\min \sum_{i, t}\left(P C_{i, t}+S C_{i, t}\right)
$$

with I the set of power plants (index i) and $\mathrm{T}$ the set of hours (index t). The production cost PC is determined by the fuel price, the $\mathrm{CO}_{2}$ emission rate, the $\mathrm{CO}_{2}$ price and the efficiency of the power plant. The efficiency of the power plant is a function of the power output. The resulting quadratic production cost curve can be linearly approximated as follows

$$
\begin{aligned}
P C_{i, t} & =A_{i} z_{i, t}+\sum_{k} F_{i, k} \delta_{i, t, k} \quad \forall i, t \\
0 & \leq \delta_{i, t, k} \leq \frac{\overline{P_{i}}-\underline{P_{i}}}{K} \quad \forall i, t, k \\
p_{i, t} & =\underline{P_{i}} z_{i, t}+\sum_{k} \delta_{i, t, k} \quad \forall i, t
\end{aligned}
$$

with $\mathrm{K}$ the set of piecewise linear approximations (index k), A the production cost at minimal power output in $[\mathrm{EUR} / \mathrm{h}]$, $\mathrm{z}$ the binary variable equal to 1 if the unit is on-line and 0 otherwise, $\mathrm{F}$ the slope of the linear approximation in [EUR/MWh], $\delta$ the power output in an interval of the linear approximation in $[\mathrm{MWh} / \mathrm{h}], \bar{P}$ the maximum power output and $\underline{P}$ the minimum power output in $[\mathrm{MW}]$ and $\mathrm{p}$ the actual power output in $[\mathrm{MWh} / \mathrm{h}]$.

The start-up cost SC is defined as

$$
\begin{gathered}
S C_{i, t} \geq C S U_{i}\left(z_{i, t}-z_{i, t-1}\right) \quad \forall i, t \\
S C_{i, t} \geq 0 \quad \forall i, t
\end{gathered}
$$

with CSU the cost per start-up in [EUR/h].

The objective function is subject to the following constraints:

Demand constraint:

$\sum_{i} p_{i, t}+\sum_{r} p d_{r, t}=d_{t}+\sum_{r} p u_{r, t}-$ wind $_{t}-$ sun $_{t}$

with $\mathrm{R}$ the set of pump units (index r), pd and pu respectively the power generated and consumed by a pump unit in $[\mathrm{MWh} / \mathrm{h}], \mathrm{d}$ the electricity demand in $[\mathrm{MWh} / \mathrm{h}]$ and wind and sun the electricity production of respectively wind and solar in $[\mathrm{MWh} / \mathrm{h}]$.

Reserve constraints:

$$
\begin{aligned}
& \sum_{i} \overline{P_{i}} z_{i, t} \geq d_{t}+r s r_{t} \quad \forall t \\
& \sum_{i} \underline{P_{i}} z_{i, t} \leq d_{t}-r s r_{t} \quad \forall t
\end{aligned}
$$

with rsr the required spinning reserve in [MW].

Generation limits and ramping constraints:

$$
\begin{gathered}
\underline{P_{i}} z_{i, t} \leq p_{i, t} \leq \overline{P_{i}} z_{i, t} \quad \forall i, t \\
p_{i, t} \leq p_{i, t-1}+R U_{i} z_{i, t-1}+S U_{i}\left(z_{i, t}-z_{i, t-1}\right) \\
+\bar{P}_{i}\left(1-z_{i, t}\right) \quad \forall i, t \\
p_{i, t-1}-p_{i, t} \leq R D_{i} z_{i, t}+S D_{i}\left(z_{i, t-1}-z_{i, t}\right) \\
+\bar{P}_{i}\left(1-z_{i, t-1}\right) \quad \forall i, t
\end{gathered}
$$


with RU the ramp-up limit, SU the start-up ramp limit, SD the shut down ramp limit and RD the ramp down limit, all in [MW].

\section{Renewable constraints:}

$$
\begin{aligned}
\text { wind }_{t} & \leq \text { wind_ava } \\
\text { sun }_{t} & \leq \text { sun_ava }
\end{aligned}
$$

with wind_ava and sun_ava the available wind and solar power in $[\mathrm{MWh} / \mathrm{h}]$. As no production cost or start-up cost is associated with renewable generation, these constraints will be binding most of the time. Only in case of curtailment, the inequality holds.

\section{Minimum down time constraint:}

$\sum_{d}\left(1-z_{i, t+d}\right) \geq D T_{i}\left(z_{i, t-1}-z_{i, t}\right) \quad \forall i, t, d=0 . . D T_{i}-1$

with DT the minimum down time of a power plant in [h].

Pump storage constraints:

$$
\begin{gathered}
\text { pen }_{r, t}=\text { pen }_{r, t-1}+p u_{r, t} \sqrt{\eta_{p}}-\frac{p d_{r, t}}{\sqrt{\eta_{p}}} \quad \forall r, t \\
0 \leq p u_{r, t} \leq p u \_ \text {max }_{r} \quad \forall r, t \\
0 \leq p d_{r, t} \leq p d \_m a x_{r} \quad \forall r, t \\
0 \leq p e n_{r, t} \leq \text { pen_max } \\
\quad \forall r, t
\end{gathered}
$$

with pen the energy content of the pump unit in [MWh], pu_max, pd_max and pen_max the maximum power generation of the pump unit in $[\mathrm{MW}]$, the maximum power consumption of the pump unit in $[\mathrm{MW}]$ and the maximum energy content in $[\mathrm{MWh}]$ respectively and $\eta_{p}$ the total efficiency of the pump unit. The factor $\sqrt{\eta_{p}}$ implies that the generation and consumption efficiency of the pump unit are equal.

Electricity generation from hydro, bio-energy and combined heat and power are modeled as demand corrections. This means that the original electricity demand is reduced by the generation from these sources. The demand d in Eq. (7) is the corrected demand. The model is calibrated in order to make the simulation results more realistic. The installed capacity of nuclear power plants and lignite fired power plants is scaled with a calibration factor to avoid overproduction from these low marginal cost plants. The rated efficiency of the different power plants is chosen so that the simulation results of the base case ${ }^{6}$ match the historical observed data with acceptable accuracy (see table II).

\section{RESULTS}

The analysis of the impact of renewable injections on cycling of conventional power plants consists of two steps. First, the change in variability in residual demand is determined. Second, the way conventional power plants meet this variable demand through cycling is determined. In a final section, the costs of conventional power plant cycling are discussed.

\footnotetext{
${ }^{6}$ In the base case, the model is run with the historical observed amount of wind and solar injections.
}

TABLE II

THE COMPARISON BETWEEN THE 2010 HISTORICAL GENERATION AND THE SIMULATED GENERATION IN THE BASE CASE SHOWS THAT THE MODEL IS PROPERLY CALIBRATED. NUC ARE NUCLEAR POWER PLANTS, SPP are Steam Power Plants, CCGT are Combined Cycle Gas TURBINES AND OCGT ARE OPEN CYCLE GAS TURBINES.

\begin{tabular}{l|cccccc}
{$[\mathrm{TWh} / \mathrm{y}]$} & NUC & SPP Lig & SPP Coal & CCGT & OCGT & Pump \\
\hline Historical & 140 & 135 & 88 & 29 & 2 & 6.6 \\
Model & 140 & 133 & 80 & 33 & 0.1 & 0.9
\end{tabular}

\section{A. Effect renewables on residual demand}

Renewable electricity injections lower the average residual demand and change the variability in residual demand. A lower residual demand implies that the intersection of the (inelastic) demand curve and the merit order shifts to the left, i.e. towards less dynamic power plants like steam power plants and nuclear power plants (see Fig. 1). The power plants on the margin, i.e. close to the intersection of the demand curve and the merit order, are the ones that cycle. Renewable injections hence affect the type of power plants that cycle.

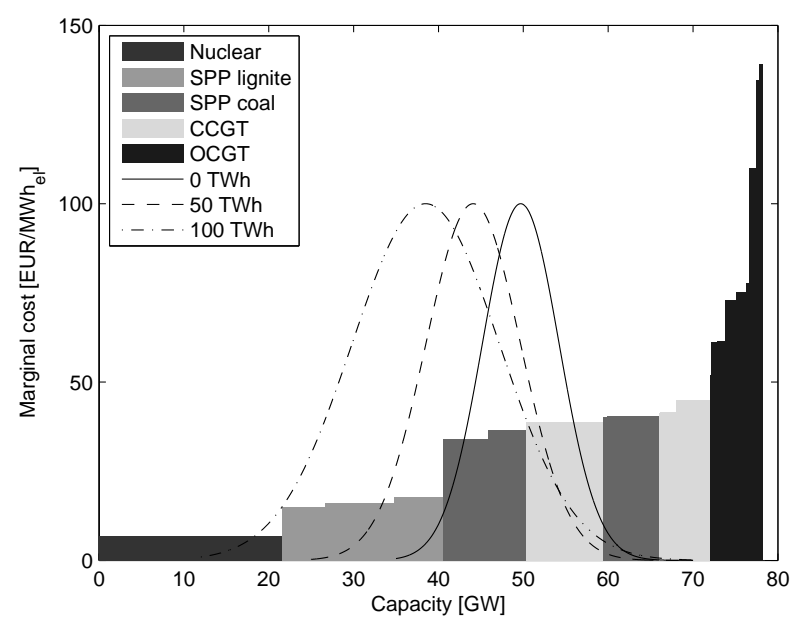

Fig. 1. The intersection of the merit order with the residual electricity demand shift towards base load plants for higher renewable injections. The curves show the normalized Gaussian distribution of the residual demand for different levels of annual wind and solar injections in 2010. SPP are Steam Power Plants, CCGT are Combined Cycle Gas Turbines and OCGT are Open Cycle Gas Turbines.

Variability in residual demand changes due to the variable character of renewable injections. The variability in demand can be measured as:

$$
\sum_{t=1}^{T-1}\left|d_{t+1}-d_{t}\right|
$$

with $\mathrm{T}$ the number of considered hours and $\mathrm{d}$ the residual electricity demand. Annual variability is expressed in [MW/year]. Often statistical parameters like the standard deviation are used to describe demand variability [24]. However, statistical parameters do not take into account the sequence in which the hourly demand data occurs. The 
variability that the conventional power plants have to meet is therefore best expressed as in Eq. (20). Renewable injections can increase or decrease the variability in residual demand, depending on the amount of injections (see the dashed line in Fig. 2). At moderate renewable injections, the midday peak in electricity demand is smoothed out, reducing the variability in the residual demand. At higher renewable injections, residual demand shows a dip in the middle of the day, increasing the variability of demand (see Fig. 3). One can conclude that the variability in residual demand first decreases with increasing renewable injections but starts rapidly to increase with 25 TWh of annual renewable injections. At 2010 historical level of wind and solar injections (50 TWh/year), the variability in residual demand increases by only $3 \%$ due to renewable injections but for $100 \mathrm{TWh} / \mathrm{year}$ wind and solar injections, variability in residual demand increases by $36 \%$.

Variability in residual demand can be smoothed out by pump units which generate power at peak demand and consume power at low demand. Likewise, curtailment of renewables reduces the variability if wind and solar power generation is decreased at moments of high demand variability. Fig. 2 shows the variability in residual demand after smoothing by both pump units and renewables curtailment (see the solid line with squares) or after renewables curtailment only (see the solid line with stars). The flexibility actually to be delivered by conventional power plants is denoted by these solid lines. It becomes clear that the impact of renewables curtailment is rather limited. With only renewables curtailment (without pump units), the required flexibility from the conventional power plant portfolio almost coincides with the variability in residual demand. Pump units on the other hand strongly reduce demand variability. With pump units, the required flexibility is lower than in the case without renewable injections for wind and solar injections up to $70 \mathrm{TWh} / \mathrm{year}$, with a maximum required flexibility reduction of $5 \%$ at 25 TWh/year wind and solar injections. At 2010 historical wind and solar generation (50 TWh/year), required flexibility is $3 \%$ lower. At $100 \mathrm{TWh} / \mathrm{year}$ wind and solar injections, the required flexibility is $6 \%$ higher compared to the case without these injections. One can conclude that the flexibility required from the conventional power plant portfolio does not change noteworthy for wind and solar injections up to $100 \mathrm{TWh} /$ year due to pump unit usage. Pump usage is implemented in the model as fully market driven. This corresponds only to a certain extent with reality, as pump usage is also used to maintain grid stability.

In summary of this section, renewable injections reduces average residual demand resulting in cycling of less dynamic power plants. Besides, renewable injections increase variability in residual demand at higher injections. However, this increased variability is mainly compensated by increased pump unit usage.

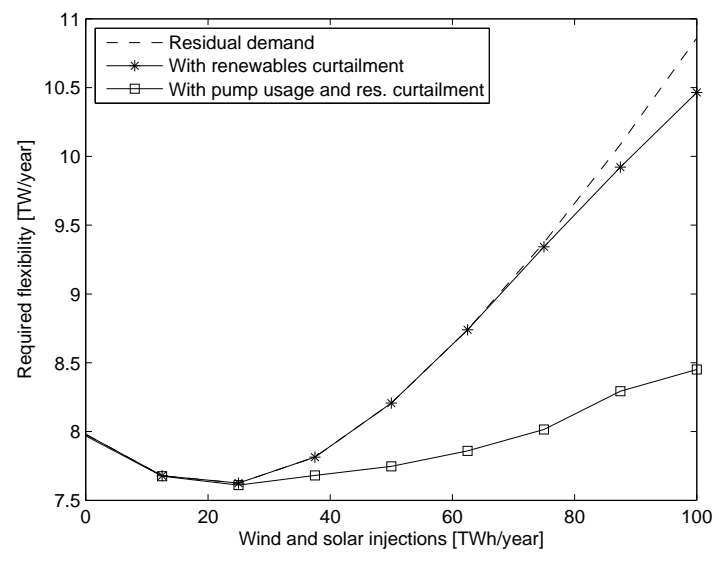

Fig. 2. Increase in variability in residual demand is largely smoothed out by pump unit usage, resulting in required conventional power plant flexibility that is influenced to a limited extent by wind and solar injections.

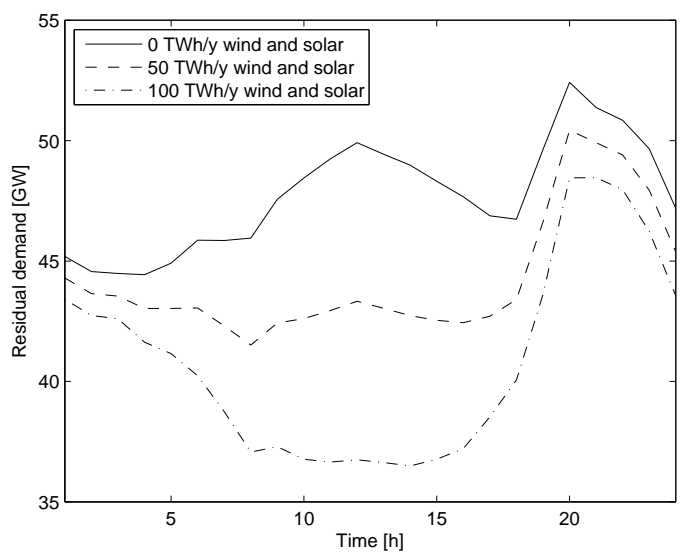

Fig. 3. The midday-peak in residual demand becomes a dip due to renewable injections (data for August 3, 2010).

\section{B. Effect renewables on conventional cycling}

The variability in residual demand after pump unit usage and renewables curtailment has to be met by the dispatchable conventional power plant portfolio. A power plant can deliver flexibility by ramping up or down and by starting up or shutting down. Although the required flexibility of the conventional power plant portfolio does not change considerably due to pump usage (see solid line with squares in Fig. 2), the way this flexibility is delivered does. The introduction of renewable injections results in a shift from mainly start-up/shut-down flexibility at zero wind and solar injections to a situation with ramping flexibility and startup/shut-down flexibility equally important at high wind and solar injections (see Fig. 4). This can be explained as follows; renewable injections move the intersection of the residual demand curve and the merit order towards less dynamic power plants. Typically, low dynamic power plants deliver ramping flexibility and high dynamic power plants deliver 
start-up/shut-down flexibility. Renewable injections thus result in more ramping flexibility and less start-up/shut-down flexibility. Note that the sum of the ramping flexibility and the start-up/shut-down flexibility does not equal the variability in residual demand. This is because at the same time, one power plant can shut down while another power plant ramps up.

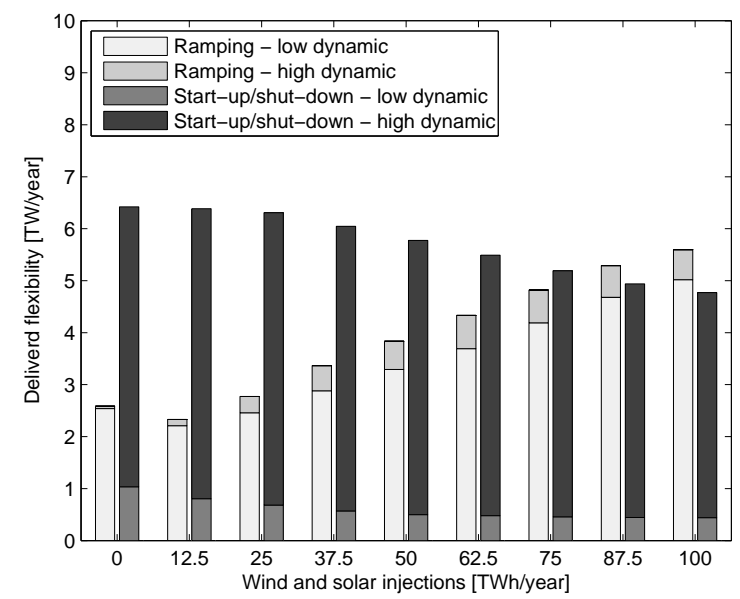

Fig. 4. Renewable injections increase the flexibility delivered by ramping of low dynamic power plants and reduce the flexibility delivered by start-up/shutdown of high dynamic power plants. The delivered flexibility is determined as the sum of the absolute values of the hourly ramping-ups/ramping-downs and start-ups/shut-downs.

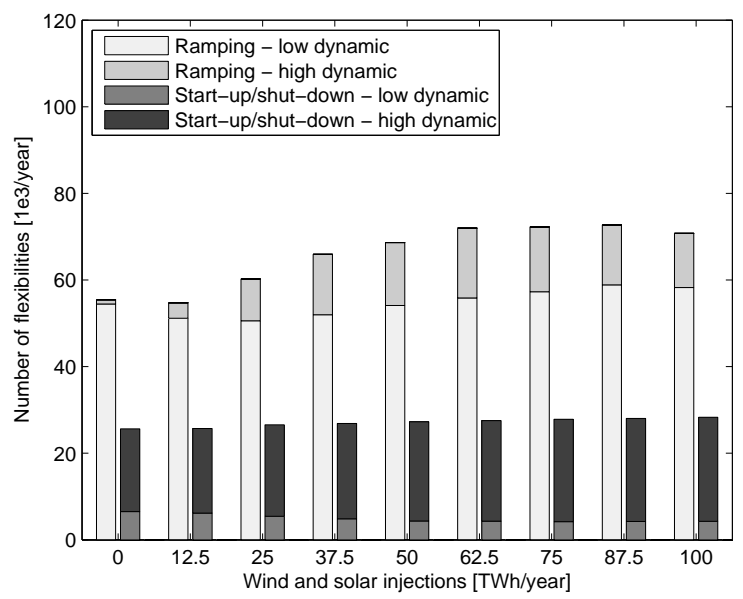

Fig. 5. The number of start-ups/shut-downs stays about constant indicating that smaller power plants start-up and shut-down due to renewable injections. The number of rampings increases but at a lower rate than the ramping flexibility, indicating that more heavy rampings occur due to renewable injections.

The evolution of number of start-ups/shut-downs and number of rampings show a different figure (see Fig. 5). Overall, the number of start-ups/shut-downs stays more or less constant while the start-up/shut-down flexibility decreases for increasing wind and solar injections. This indicates that

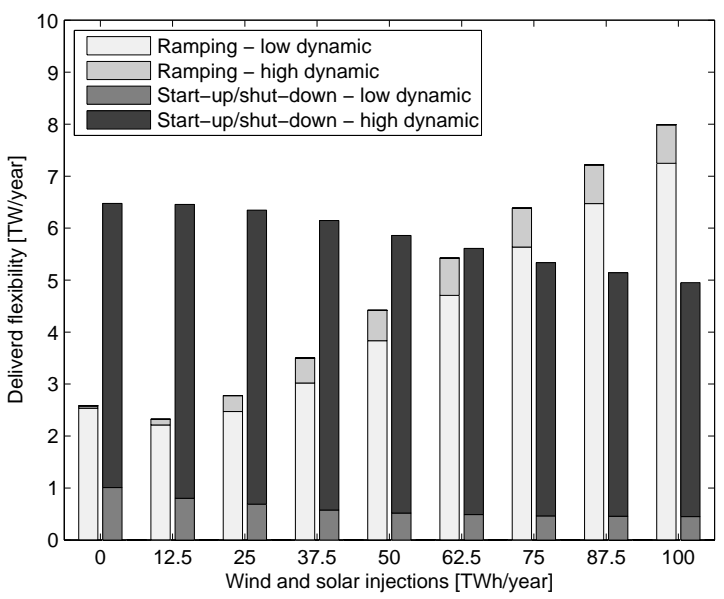

Fig. 6. Without pump units, the increase in required flexibility is fulfilled by ramping of low dynamic power plants. The delivered flexibility is determined as the sum of the absolute values of the hourly ramping-ups/ramping-downs and start-ups/shut-downs.

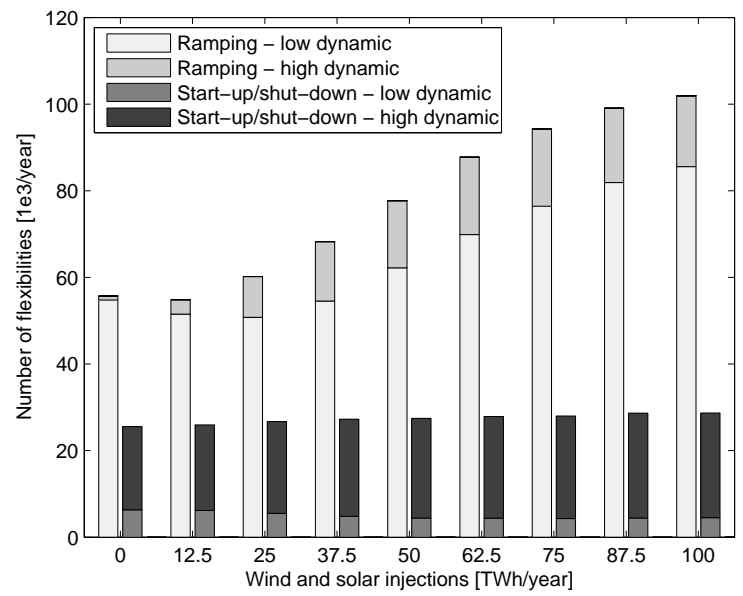

Fig. 7. Without pump units, more rampings of mainly low dynamic power plants occur compared to a case with pump units. The increase in number of rampings is smaller than the increase in ramping flexibility, indicating that more heavy ramping occurs.

the flexibility per start-up/shut-down decreases. The number of rampings increases but at a lower rate than the ramping flexibility $^{7}$, implying that the flexibility per ramping increases. To put it in other words, renewable injections lead to heavier ramping of power plants.

If a case without pump units is considered, the flexibility required from the conventional power plant portfolio increases considerably for increasing renewable injections (see solid line with stars in Fig. 2). However, the conclusions drawn for the

\footnotetext{
${ }^{7}$ The number of rampings increases from 55,423 at zero wind and solar injections to 70,788 at $100 \mathrm{TWh} /$ year wind and solar injections, which is an increase of $28 \%$. Delivered ramping flexibility increases from 2.6 TW/year at zero wind and solar injections to $5.6 \mathrm{TW} / \mathrm{year}$ at $100 \mathrm{TWh} / \mathrm{year}$ wind and solar injections, which is an increase of $116 \%$.
} 
TABLE III

OVERVIEW OF DIFFERENT COSTS INVOLVED IN CONVENTIONAL POWER PLANT CYCLING. THE AVERAGE OPERATING POINT IS THE AVERAGE LOAD FACTOR WHEN THE POWER PLANT IS IN OPERATION. THE RAMPING COST IS THE FUEL AND CO 2 EMISSION COST DUE TO LOWER AVERAGE OPERATING POINTS.

\begin{tabular}{l|ccccc} 
& \multicolumn{5}{|c}{ Wind and solar injections [TWh/year] } \\
& 0 & 25 & 50 & 75 & 100 \\
\hline Production cost [Mio EUR] & 9,348 & 8,457 & 7,639 & 6,952 & 6,407 \\
Start-up cost [Mio EUR] & 9.51 & 9.83 & 9.70 & 9.74 & 9.74 \\
Ramping cost [Mio EUR] & 49 & 93 & 180 & 253 & 300 \\
$\quad$ Average operating point & & & & & \\
$\quad$ Low dynamic plants [\%] & 94.7 & 87.5 & 82.3 & 76.6 & 71.0 \\
$\quad$ High dynamic plants [\%] & 99.7 & 95.7 & 83.4 & 72.3 & 64.7 \\
Effective number of operating hours & & & & & \\
$\quad$ Conventional portfolio [h] & 5,211 & 4,845 & 4,482 & 4,123 & 3,810 \\
$\quad$ Low dynamic plants [h] & 7,486 & 7,392 & 7,043 & 6,577 & 6,104 \\
$\quad$ High dynamic plants [h] & 2,761 & 1,976 & 1,546 & 1,283 & 1,142
\end{tabular}

case with pump units remain the same. The only difference is that the increase in ramping is more pronounced as the required flexibility is higher. Start-up/shut-down flexibility decreases and ramping flexibility, mainly coming from low dynamic power plants, increases with increasing wind and solar injections (see Fig. 6). Without pump units, the increase in ramping flexibility is higher than with pump units. The number of start-ups/shut-dows remains the same while the number of rampings strongly increase (see Fig. 7). Without pump units, more rampings occur compared to the case with pump units. The increase in number of rampings is however less than the increase in ramping flexibility ${ }^{8}$, indicating that more heavy ramping occurs.

\section{Cost considerations}

This section deals with the costs related to cycling in case of demand smoothing by pump units. The start-up cost stays about the same when renewable injections are introduced (see table III) as the number of start-ups barely changes due to wind and solar injections (see Fig. 5). Note that only the fuel and $\mathrm{CO}_{2}$ emission cost for a start-up is considered. The costs related to deterioration of components due to start-ups and shut-downs are not taken into account. To put the level of start-up cost in perspective, one can compare this cost with the production cost. The production cost is three orders of magnitude larger than the start-up cost. Annual wind and solar injections of $50 \mathrm{TWh}$ result in an increase in start-up costs of 0.19 million EUR and in a production cost decrease of about 1,700 million EUR. The effect of renewable injections on production costs is thus four orders of magnitude larger than the effect on start-up costs. These numbers depend on the assumed cost per start-up. However, the relationship between start-up costs imposed on the operators and the resulting total start-up cost is not straightforward. Doubling the start-up cost probably results in less start-ups and a total start-up cost which is less than doubled.

\footnotetext{
${ }^{8}$ The number of rampings increases from 55,423 at zero wind and solar injections to 101,924 at $100 \mathrm{TWh} /$ year wind and solar injections, which is an increase of $84 \%$. Delivered ramping flexibility increases from 2.6 TW/year at zero wind and solar injections to $8.0 \mathrm{TW} / \mathrm{year}$ at $100 \mathrm{TWh} / \mathrm{year}$ wind and solar injections, which is an increase of $208 \%$.
}

In the model, no cost is allocated to ramping of power plants. It is however possible to determine a sort of ramping cost. Ramping is closely related to partial load operation as ramping implies that the power plant is not always operating at its rated efficiency. The average operating point of each type of power plant decreases considerably due to renewable injections (see table III). The average operating point is defined as the average load factor when the power plant is online $^{9}$. A decrease in average operating point goes along with a decrease in average operating efficiency of the power plant, resulting in higher production costs. Hence, the ramping cost could be calculated as the difference in production cost between the simulated scenario and a scenario with the same generation of each power plant but at rated efficiencies. This ramping cost raises up to 180 million EUR for $50 \mathrm{TWh} / \mathrm{year}$ wind and solar injections and 300 million EUR for 100 TWh/year wind and solar injections. This cost is thus about one to two orders of magnitude larger than the start-up cost. The ramping cost is already incorporated in the production cost, meaning that this cost in not an additional cost on top of the production cost and the start-up cost.

Another issue related to costs are the effective number of operating hours $(\mathrm{ENOH})^{10}$. Renewable injections result in decreasing ENOHs for conventional power plants (see table III). This decrease in effective operating hours is larger for high dynamic power plants, especially in relative terms, and is related to the issue of missing money. Renewable injections diminish the time during which power plant operators can recover their fixed costs.

\section{CONCLUSiON}

Under the assumptions made in this paper, the conclusion is that at wind and solar injections in line with the European renewable target, the flexibility required from the conventional power plant portfolio is hardly increased due to increased

\footnotetext{
${ }^{9}$ The load factor is the ratio of the actual power output and the maximum possible power output.

${ }^{10}$ The ENOH is defined as the number of hours that a unit has to operate at rated power output to generate its annual electricity production.
} 
pump unit usage. However, the way required flexibility is delivered by conventional power plants is affected by renewable injections. As renewable injections push more base load plants on the margin, these low dynamic plants have to cycle instead of more dynamic combined cycle units.

The impact of renewable injections on cycling of conventional power plants consists of two aspects. First, renewable injections change the required flexibility of the conventional power plant portfolio. Second, renewable injections shift the intersection of the demand curve and the merit order to the left, meaning that more base load plants appear on the margin and deliver flexibility.

The analysis shows that variability in residual demand decreases at low amounts of wind and solar injections as the midday-peak in the electricity demand is smoothed out by wind and especially solar. At higher amounts of wind and solar injections the variability in demand starts to increase rapidly. The variability in residual demand is decreased considerably by pump unit usage and to a lesser extent by renewables curtailment. Therefore the flexibility that conventional power plants actually have to deliver does not change that much in case of wind and solar injections.

The way conventional power plants deliver flexibility by cycling does change due to wind and solar injections. At low renewable injections, most flexibility comes from high dynamic power plants (combined cycle power plants) starting up and shutting down. The introduction of renewable injections leads to more flexibility coming from ramping of low dynamic power plants (steam power plants) and less startup/shut-down flexibility from high dynamic power plants. Start-up flexibility decreases due to wind and solar injections but the number of start-ups stays about the same, resulting in about constant start-up costs for different levels of renewable injections. Ramping flexibility increases due to wind and solar injections as result of more heavy ramping. Closely related to the increase in ramping is a decrease in average load factor, which translates into lower operating efficiencies of conventional plants and an increase in production cost. This increase in production cost is however small compared to the fuel cost and $\mathrm{CO}_{2}$ emission cost savings due to wind and solar injections.

Further research will examine the effect of higher cycling costs imposed to conventional power plants. In this paper, only a moderate start-up cost is taken into account in the unit commitment decision. It would be interesting to assess the effect of generators taking into account higher start-up costs and also ramping costs (representing the costs of component degeneration). One could expect that at higher cycling costs, more renewables curtailment and pump unit storage are used to limit cycling. Another interesting extension of the current model is to take into account the unpredictability of wind and solar. As such, the unit commitment decision would be made based on the predicted wind and solar injections, while dispatch happens based on the actual injections. One can expect the cycling costs to increase if unpredictability is taken into account as well.

\section{REFERENCES}

[1] European Wind Energy Association (EWEA), "EU reaches 100 GW wind power milestone", Available: <http://www.ewea.org/pressreleases $>$.

[2] EWEA, "Wind in Power - 2011 European Statistics", Tech. Rep., European Wind Energy Association (EWEA), 2011.

[3] EPIA, "Global Market Outlook for Photovoltaics until 2016", Tech. Rep., European Photovoltaic Industry Association (EPIA), 2012.

[4] P. Luickx, E. Delarue and W. D'haeseleer, "Considerations on the backup of wind power: Operational backup", Applied Energy, vol. 85 no. 9, pp. 787-799, 2008.

[5] P. Meibom, C. Weber, R. Barth and H. Brand, "Operational costs induced by fluctuating wind power production in Germany and Scandinavia", IET Renewable Power Generation, vol. 3, no. 1, pp. 75-83, 2009.

[6] H. Holttinen and J. Pedersen, "The effect of large scale wind power on a thermal system operation", in Proceedings of the 4th International Workshop on Large-Scale Integration of Wind Power and Transmission Networks for Offshore Wind Farms, 2003.

[7] E. Denny and M. O'Malley, "The impact of carbon prices on generationcycling costs", Energy Policy, vol. 37, pp. 1204-1212, 2009.

[8] S. Lefton, P. Besuner and G. Grimsrud, "Understand what it really costs to cycle fossil-fired units", Aptech Engineering Services Inc, 1997.

[9] N. Troy, E. Denny and M. OMalley, "Base-load cycling on a system with significant wind penetration", IEEE Transactions on Power Systems, vol. 25, no. 2, pp. 1088-1097, 2010.

[10] N. Kumar, P. Besuner, S. Lefton, D. Agan and D. Hilleman, "Power plant cycling costs", Tech. Rep., Intertek APTECH, Sunnyvale, California, 2012.

[11] K. Bruninx, D. Madzharov, E. Delarue and W. D'haeseleer, "Impact of the german nuclear phase-out on Europe's electricity generation - a comprehensive study", Working paper submitted to Energy Policy, 2012.

[12] S. Riedel and H. Weigt., "German electricity reserve markets", Electricity Markets Working Papers, 2007.

[13] P. Martens, "Integratie van Carbon Capture and Storage in het elektriciteitsproductiepark", Master's thesis, Univeristy of Leuven (KU Leuven), 2010.

[14] European Climate Foundation, "Roadmap 2050: Volume 1 - Technical Analysis", Tech. Rep., ECF, 2010.

[15] B. Ummels, M. Gibescu, E. Pelgrum, W. Kling and A. Brand, "Impacts of wind power on thermal generation unit commitment and dispatch", IEEE Transactions on Energy Conversion, vol. 22, no. 1, pp. 44-51, 2007.

[16] Umweltbundesamt, "Datenbank Kraftwerke in Deutschland", Available: $<$ http://www.umweltbundesamt.de $>, 2012$.

[17] ENTSO-E, "European network of transmission system operators for electricity, data portal", Available: $<$ http://www.entsoe.eu/resources/data-portal>, 2012.

[18] Amprion, "Electricity transmission system operator in Germany", Available: < http://www.amprion.de>, 2012.

[19] $50 \mathrm{~Hz}$, "Electricity transmission system operator in Germany", Available: <http://www.50hertz.de>, 2012.

[20] Tennet, "Electricity transmission system operator in Germany", Available: < http://www.tennettso.de >, 2012.

[21] Photovoltaic Geographical Information System, "Joint research centre of the european commission", Available: $<$ http://re.jrc.ec.europa.eu/pvgis >, 2011.

[22] Eurelectric, "Power statistics, 2010 edition", Tech. Rep., 2010 Eurelectric.

[23] M. Carrión and J.M. Arroyo, "A computationally efficient mixed-integer linear formulation for the thermal unit commitment problem", IEEE Transactions on Power Systems, vol. 21, no. 3, 2006.

[24] H. Holttinen., "Impact of hourly wind power variations on the system operation in the Nordic countries", Wind Energy, vol. 8, pp. 197-218, 2005. 